\title{
Coordinated decline in photosynthesis and hydraulic conductance during drought stress in Zea
}

mays

Sean M. Gleason*, Dustin R. Wiggans, Clayton A. Bliss, Louise H. Comas, Mitchell Cooper, Kendall C. DeJonge, Jason S. Young, Huihui Zhang

USDA-ARS, Water Management Research Unit, 2150 Center Ave, Build D, Suite 320, Fort Collins, CO 80526, USA

* Corresponding author. Tel.: +1 9704927411

E-mail address: sean.gleason55@gmail.com

\begin{abstract}
Present efforts to improve maize performance in water-limited environments are aggressively pursuing leaf-level traits, such as quantum efficiency, mesophyll osmoregulation, and stress-protein responses. However, it is possible that improvement of these traits will lead directly to hydraulic failure if hydraulics and photosynthesis are closely aligned. Here, we address the whole plant response to drought stress and ask if photosynthetic and hydraulic traits appear bundled together as a "coordinated" response, or if these traits operate largely independently of one another. Xylem conductance of leaves and stems, whole plant conductance, stomatal conductance, rate of electron transport (ETR), maximal catalytic rate of phosphoenolpyruvate carboxylase $\left(\mathrm{V}_{\mathrm{pmax}}\right)\left(\mathrm{EC}\right.$ 4.1.1.31), and net $\mathrm{CO}_{2}$ assimilation $\left(\mathrm{A}_{\max }\right)$ were measured in maize plants subjected to contrasting levels of drought stress in greenhouse and field experiments.

Photosynthetic traits $\left(\mathrm{A}_{\max }, \mathrm{ETR}, \mathrm{V}_{\mathrm{pmax}}\right.$ ), hydraulic traits (whole plant and stem conductance) and stomatal conductance were all reduced by $>80 \%$ as leaf water potentials declined below $-3.0 \mathrm{MPa}$. Furthermore, $83 \%$ of the variation associated with the photosynthetic and hydraulic traits measured in this study was
\end{abstract}


explained by a single principal component, revealing a remarkable degree of alignment among them. Whole plant transpiration rates recovered to ca $90 \%$ of maximal values $4 \mathrm{~d}$ after lifting severe drought stress $\left(\Psi_{\text {leaf }} \approx-3.5 \mathrm{MPa}\right)$. Closely aligned hydraulic, photosynthetic, and stomatal responses to drought stress suggest that improvements to individual traits, in isolation to each other, may lead to the loss of plant functioning (e.g. water transport) rather than leading to marked improvements in growth.

Keywords: gas exchange; chlorophyll fluorescence; water transport; whole plant conductance; xylem conductance; stomata 


\section{Introduction}

Cellular and leaf-level responses to drought stress are now reasonably well understood and have led to improvements in plant performance in water-limited environments. The genetic underpinnings of osmoregulation (Robin et al., 2003; Singh et al., 2015; Umezawa et al., 2006), the production of protective proteins and chaperones (Castiglioni et al., 2008; Lee et al., 2015; Umezawa et al., 2006), and maintenance of stomatal and photosynthetic functioning during late-stage drought stress, i.e., "stay-green" (Almeida et al., 2014; Kotakis et al., 2014; Yan et al., 2004) are being resolved and have already contributed meaningfully to food production. Many of these efforts have led to sustained photosynthesis and water use during stress. Although it is well known that the maintenance of these processes during drought stress is dependent upon the delivery of water to the sites of photosynthesis and also the stomata, the linkage between photosynthesis and hydraulic supply has rarely been addressed in either breeding or gene editing efforts to improve crop species.

Conceptually, a plant can be viewed as a water-hungry biomass factory that is therefore susceptible to water shortage. Whole plant functioning can be broken into three broad physiological processes: 1) access to $\mathrm{CO}_{2}$ (stomatal and mesophyll conductance), 2) the machinery of photosynthesis itself, e.g., photosystem II, $\mathrm{CO}_{2}$ concentration mechanism (in the case of $\mathrm{C}_{4}$ plants) and the BensonCalvin cycle, and 3) the supply of water (xylem functioning). Stomatal conductance is perhaps the beststudied component of the whole plant response to drought stress. Conductance of $\mathrm{CO}_{2}$ through the stomata and mesophyll tissue must occur for carbon fixation to take place, but this also results in desiccation of the mesophyll and reduction in leaf water potential. Water supplied through the xylem feeds the process of evaporation taking place in the mesophyll, and therefore, ensures a steady supply of $\mathrm{CO}_{2}$ through the stomata. The cues triggering stomatal closure in angiosperms are still incompletely understood (Damour et al., 2010; Medlyn et al., 2011), but include atmospheric aridity (vapor pressure deficit; VPD) (Aphalo and Jarvis, 1991), intercellular $\mathrm{CO}_{2}$ concentration (Ainsworth and Rogers, 2007), soil aridity (soil water potential, $\Psi_{\text {soil }}$ (Brodribb and McAdam, 2011), and may also include leaf water 
potential ( $\left.\Psi_{\text {leaf }}\right)$ (Bond and Kavanagh, 1999; Tuzet and Leuning, 2003), although the role of $\Psi_{\text {leaf }}$ is still unclear (Ball et al., 1987; Zhang et al., 2013).

It is likely that more negative $\Psi_{\text {leaf }}$ is associated with coordinated reductions in photobiochemistry, stomatal conductance, and net $\mathrm{CO}_{2}$ assimilation in both $\mathrm{C}_{3}$ and $\mathrm{C}_{4}$ species (Grassi and Magnani, 2005; Markelz et al., 2011; Vico and Porporato, 2008), but whether net $\mathrm{CO}_{2}$ assimilation under drought stress is limited more by low internal $\mathrm{CO}_{2}$ partial pressure or by decline in leaf water content is still debated (Flexas and Medrano, 2002; Ghannoum, 2009; Grassi and Magnani, 2005). However, most research supports the idea that $\mathrm{CO}_{2}$ assimilation is first inhibited by limited diffusion of $\mathrm{CO}_{2}$ from the atmosphere to the initial carboxylation sites in the mesophyll, and then by biochemical inhibition or down-regulation under more severe drought stress (Flexas and Medrano, 2002; Pinheiro and Chaves, 2011).

Among the three broad physiological systems (stomatal conductance, photosynthesis, and water transport), water transport from the soil to the sites of photosynthesis is by far the least studied among crop plants (Gleason, 2015). Vascular plants require a water transport system (xylem tissue) that is both efficient and also safe from embolization, i.e., the filling of water-filled conduits with gas, and subsequent failure. Although efficient and safe xylem are known outcomes of natural selection in various habitats (Choat et al., 2012; Gleason et al., 2012; Gleason et al., 2013; Lens et al., 2013), the importance of xylem efficiency and safety has rarely been investigated in agricultural settings. In fact, during the preparation of this manuscript we evaluated 18 published reviews on transgenic and breeding efforts to improve drought tolerance in crops, and not a single report includes the word "xylem" or addresses water transport (Gleason, 2015). This may be because little heritable variation in xylem traits has been found (Jupa et al., 2013; Lamy et al., 2011; Lamy et al., 2014; Rosner et al., 2007; Wortemann et al., 2011). Nevertheless, hydraulic resistance in xylem tissue remains a significant component of whole plant resistance (Nardini and Salleo, 2000; Sack et al., 2003), and as such, is a common source of hydraulic failure and death during drought stress (Choat, 2013; Lens et al., 2013; Rowland et al., 2015). 
We might expect photosynthesis, stomatal regulation, and xylem conductance to be ineluctably linked with one another via natural selection, as this would provide matched hydraulic and photosynthetic capacities in all habitats (Mencuccini et al., 2015). For example, natural selection acting on plants in wet and arid environments should result in hydraulic and photosynthetic capacities "tuned" to the availability and use of water in these environments. If we accept this, then we should not expect improvements to photosynthetic, stomatal, or hydraulic functioning, in isolation of each another, to result in marked improvements in whole plant performance.

We set out to quantify the amount of covariation existing among photosynthetic, hydraulic and stomatal conductance traits during drought stress to evaluate the possible linkage among them. First, we asked how much is hydraulic conductance (whole plant and stem xylem) reduced during dry-down and how are reductions in whole plant conductance aligned with increasing leaf drought stress (measured as leaf water potential; $\left.\Psi_{\text {leaf }}\right)$ ? Second, we asked how well photosynthetic functioning (ETR, $V_{\text {pmax }}, A_{\max }$, maximal stomatal conductance) was aligned with increasing leaf drought stress? Third, we asked, are reductions in whole plant conductance aligned with photosynthetic and stomatal functioning? Lastly, we asked how quickly does whole plant transpiration recover following severe drought stress?

\section{Materials and methods}

\subsection{Genotype selection and greenhouse growing conditions}

We chose inbred B73 (Zea mays L.) as our test genotype because its deoxyribonucleic acid sequence is completely known (Schnable et al., 2009) and it is used in genome-wide association studies (McMullen et al., 2009; Yu et al., 2008) to facilitate the identification of genes coding for particular physiological and structural traits (Peiffer et al., 2014). Identity of genes and the regulatory networks of drought tolerance in maize is a primary goal for agriculture and the results reported here are presently being used to facilitate these efforts. 
Large pots (13.7-L) were filled to within $5 \mathrm{~cm}$ of the top rim with TurFace Greensgrade (PROFILE Products, LLC., Buffalo Grove, IL, USA) on 3 November 2014. Three B73 seeds were sown in each pot to a depth of $2.5 \mathrm{~cm}$ on 21 November and then reduced to one plant per pot two weeks later. Filled pots were arranged into two rows of 29 pots on two greenhouse tables for a total of 116 pots (four rows of 29 pots). Each row of pots consisted of seven border plants on each end with 15 experimental plants in-between. High pressure sodium lights operated from $0600 \mathrm{~h}$ to $2000 \mathrm{~h}$ and provided an additional photosynthetic photon flux density (PPFD) of $\approx 300 \mu \mathrm{mol} \mathrm{m}^{-2} \mathrm{~s}^{-1}$. The PPFD sensors in the greenhouse were not recording properly during the experiment, however, the following year a similar experiment (same greenhouse, same lights) was performed during the same months. Maximum daily PPFD values during this experiment were $1187 \mu \mathrm{mol} \mathrm{m}^{-2} \mathrm{~s}^{-1}(\mathrm{SD}=191)$ with mean values at 0800,1200 , and 1700 hours of $488 \mu \mathrm{mol} \mathrm{m} \mathrm{s}^{-1}(\mathrm{SD}=114), 989 \mu \mathrm{mol} \mathrm{m}^{-2} \mathrm{~s}^{-1}(\mathrm{SD}=265)$, and $370 \mu \mathrm{mol} \mathrm{m} \mathrm{m}^{-2}(\mathrm{SD}=$ 22), respectively. Temperature was allowed to range between 13 and $27^{\circ} \mathrm{C}$. Mean daily VPD of the atmosphere at $1000 \mathrm{~h}, 1230 \mathrm{~h}$, and $1400 \mathrm{~h}$ was $2.45,3.24$, and $2.88 \mathrm{kPa}$, respectively.

All pots were watered to holding capacity every morning at $0500 \mathrm{~h}$ for six minutes utilizing a drip-line irrigation system operated via battery timer (RBC7000, DIG Corp, Vista, CA, USA), a backflow preventer, 0.21-MPa pressure regulator, and in-line filter connected to $1.91 \mathrm{~cm}$ diameter poly tubing. One 7.57 $\mathrm{L} \mathrm{h}^{-1}$ emitter (Rainbird Corp., Tucson, AZ, USA) was attached to the main poly-line using $0.64 \mathrm{~cm}$ diameter distribution tubing. Fertilizer was applied by top-dressing each pot with UFLEXX 28-3-10 Turf Fertilizer (Howard Johnson's Enterprises, Inc., Milwaukee, WI, USA) to obtain $200 \mathrm{mg} \mathrm{N} \mathrm{kg}{ }^{-1}$ dry soil on 3 November, 1 December, and on 5 January. Additional fertilization consisted of each pot receiving 500 $\mathrm{mL}$ of general purpose water soluble fertilizer (20-20-20) mixed to obtain $15.2 \mathrm{mg} \mathrm{N} \mathrm{kg}^{-1}$ dry soil on 14 November, 20 November, and 17 December.

To assess plant response to drought stress, a dry-down experiment was started on 5 January 2015 by removing the emitters from 30 randomly selected pots. The 30 pots receiving full irrigation were considered "fully-watered" treatments. Measurements during dry-down (described below) were performed over a 10-day period (16 January to 26 January), whilst treatments remained in effect. Whole 
plant transpiration during this time was measured (2-g precision) continuously by placing four plants from each irrigation treatment on digital balances (Acme LBK 65A, Acme Scale Systems Inc., Villa Park, IL, USA) (cf. Fig. 1). To eliminate soil evaporation from these eight plants, the tops of the pots were tightly covered with white plastic.

To assess the rate of recovery from drought stress following the dry-down, all plants that were not destructively sampled were re-watered to field capacity on 27 January and remained on drip irrigation for 49 days. On March 16, emitters were randomly removed from four pots and these plants were allowed to dry-down a second time for a further 13 days, at which point they were exhibiting severe drought stress $\left(\Psi_{\text {leaf }}=-3.6 \mathrm{MPa} \pm 0.35 \mathrm{SD}\right)$. These plants were then re-watered (March 29) and the recovery rate of whole plant transpiration was monitored for the next five days by measuring mass loss from plasticcovered pots placed on laboratory balances, as described above.

\subsection{Whole plant loss of conductance curves}

Greenhouse plants with differing values of $\Psi_{\text {leaf }}$ were sampled each day during the first dry-down period. Generally, 4 plants from each treatment (fully-watered vs drought-stress) were measured each day at ca $0600 \mathrm{~h}, 0830 \mathrm{~h}, 1000 \mathrm{~h}$, and $1130 \mathrm{~h} . \Psi_{\text {leaf }}$ was measured when plants were removed from the greenhouse bench with a pressure chamber (Model 3005, Soil Moisture Equipment Corp, Santa Barbara, CA, USA). Plants were then given $4 \mathrm{~L}$ of water and allowed to drain for ca 5 min. The top of each pot was then covered with white plastic (leaving shoots and leaves exposed) to eliminate evaporation from the soil surface and the pot was placed on a digital balance (Adam CBK 70a, Adam Equipment Inc, Oxford, CT, USA) inside a growth chamber (Conviron model BDR16, Controlled Environments Ltd., Canada), where temperature, PPFD, and relative humidity were set to $25^{\circ} \mathrm{C}, 250 \mu \mathrm{mol} \mathrm{m} \mathrm{m}^{-2} \mathrm{~s}^{-1}$, and $50 \%\left(\mathrm{VPD}_{\text {air }} \approx 1.5\right.$ $\mathrm{kPa}$ ), respectively. Whole plant transpiration $\left(\mathrm{E}_{\text {plant }}\right.$ ) was measured for ca $20 \mathrm{~min}$. Whole plant hydraulic conductance $\left(\mathrm{K}_{\text {plant }}\right)$ was calculated as (Stiller et al., 2003):

$$
K_{\text {plant }}=\frac{E_{\text {plant }}}{\Psi_{\text {soil }}-\Psi_{\text {leaf }}}
$$


$\Psi_{\text {soil }}$ was assumed zero, as soils were saturated with water immediately prior to measurement. $\Psi_{\text {leaf }}$ was measured again when plants were taken out of the growth chamber. Although the assumption that $\Psi_{\text {soil }}$ was equal to zero after watering is not exactly correct (variation in soil conductance will modify it somewhat), we argue that these very small differences in $\Psi_{\text {soil }}$ would have a negligible effect on $\mathrm{K}_{\text {plant }}$ considering the significant variation in $\mathrm{E}_{\text {plant }}$ and $\Psi_{\text {leaf, }}$ which both varied more than an order of magnitude across plants. Transpiration reached steady-state quickly and with no evidence of recovery (in the case of stressed plants) during measurements in the constant-climate chamber, i.e., the rate of water loss was linear during the entire measurement time (ca $20 \mathrm{~min}$ ) (Fig. S1).

$\mathrm{K}_{\text {plant }}$ was expressed per unit leaf area (leaf-specific $\mathrm{K}_{\text {plant }}$ ) by dividing $\mathrm{K}_{\text {plant }}$ by the leaf area of each plant. To determine the leaf area of measurement plants, an average leaf mass per unit leaf area (LMA) was obtained by scanning leaf areas of four plants (different from measurement plants) on a leaf area meter (Model 3100, LI-COR Bioscience, Lincoln, Nebraska USA), drying the leaves to constant mass and weighing them. Leaf mass of measurement plants was then divided by LMA to convert leaf mass to leaf area. Whole plant conductance (normalized by leaf area) was plotted against $\Psi_{\text {leaf }}$ to obtain vulnerability curves (cf. Fig. 2). Data were fitted with an exponential sigmoid equation after Pammenter and Vander Willigen (1998) using the “nls” function in R (R Core Team, 2015).

\subsection{Stem specific conductivity measured on field plants}

In addition to measuring the loss of whole plant conductance with increasing drought stress (described above), we also measured the loss of conductance in stems in B73 plants grown in the field. We include these data to place the results of our greenhouse experiment in context - similar losses in conductivity (whole plant and stem) can be expected under drought stress in both field and greenhouse plants. We note that our stem conductivity measurements reflect the integrated functioning of vessels whereas our whole plant conductance measurements reflect both vascular and extra-vascular resistance components, which can differ in both angiosperms (Choat et al., 2005) and gymnosperms (Charra-Vaskou et al., 2012). 
Briefly, specific conductivity $\left(\mathrm{K}_{\mathrm{s}}\right)$ was measured on stems of B73 plants grown in the field (5 August - 14 September, 2014). Fully watered plants were collected from the field in the early morning (ca 0600). $\Psi_{\text {leaf }}$ at the time of collection was $>-0.3 \mathrm{MPa}$ in all cases. Whole plants (without roots) were allowed to dry on a laboratory bench and brought into an adjoining laboratory for measurement after they

had reached a desired $\Psi_{\text {xylem. }}$ Immediately prior to measurement, plants were placed into a plastic bag and allowed to equilibrate for ca $20 \mathrm{~min}$. After equilibration, one upper leaf (generally the $2^{\text {nd }}$ collared leaf from the top) was cut free from the plant and transferred straightaway to a pressure chamber (Model 3005, Soil Moisture Equipment Corp, Santa Barbara, CA, USA) for $\Psi_{\text {leaf }}$ measurement.

At the same time that leaves were being measured for $\Psi_{\text {leaf }}$, stem hydraulic conductance was measured. A stem section (ca $200 \mathrm{~mm}$ ), with an intact node present on each end (bordered pits are located in the nodes of maize) (Shane et al., 2000) was cut free from the base of the stem under water and allowed 2-5 min to release tension (Wheeler et al., 2013). The nodes where then cut free from the stem section underwater, leaving a short internode section $(\mathrm{ca} 160 \mathrm{~mm})$. This trimmed segment was then connected to a Sperry apparatus via $15.0 \mathrm{~mm}$ (inside diameter) silicon tubing (McMaster-Carr, Elmhurst, IL, USA) and conductance was measured across a 2-kPa pressure gradient using filtered deionized water. Parafilm and mounting putty were used to ensure a water-tight fit between tube and stem. Conductance normalized by the length and cross-sectional area of the stem, pressure gradient, and corrected for water temperature, i.e., stem-specific conductivity was calculated. X-ray microtomography ( $\mu$-CT) was used to verify that gas embolization was the primary cause of reduction in specific conductivity (Fig. S2).

\subsection{Gas exchange and chlorophyll fluorescence}

Between two and four plants, from each treatment, each day (16 January - 23 January in the greenhouse and 8 August -9 September in the field) were selected for constructing " $\mathrm{A} \sim \mathrm{C}_{\mathrm{i}}$ " curves. The first topmost collared leaf was cut from the plant using sharp scissors, re-cut under water with a razor blade, and then set into the fluorescence/gas exchange cuvette (LI-6400-40, LI-COR Biosciences, Lincoln, Nebraska, USA), with the cut end remaining under water. Irradiance was ramped up in steps of ca $200 \mu \mathrm{mol} \mathrm{m}^{-2} \mathrm{~s}^{-1}$ 
until the maximal $\mathrm{CO}_{2}$ assimilation rate $\left(\mathrm{A}_{\max }\right)$ was achieved for each leaf. For drought-stressed plants this process could take up to one hour to achieve a steady $\mathrm{A}_{\max }$. Chlorophyll fluorescence and gas exchange were measured on excised leaves for two reasons. Firstly, construction of $A \sim C_{i}$ curves would have been impossible at the leaf water potentials sampled in this study $(<-3.5 \mathrm{MPa})$ and subsequent stomatal conductance very near zero. Secondly, data from our lab as well as others have shown that gas exchange can be measured effectively on excised maize leaves (Leakey et al., 2006; Markelz et al., 2011). We also wanted to eliminate short-term reductions in $\mathrm{CO}_{2}$ assimilation resulting from reduced mesophyll conductance (desiccated leaves) (Grassi and Magnani, 2005; Hanson and Hitz, 1982), and focus on meaningful reductions in photochemical functioning resulting the up/down-regulation of enzyme activities, which has been shown to require at least several hours in both $\mathrm{C}_{3}$ and $\mathrm{C}_{4}$ plants (McCormick et al., 2008; Song et al., 2014).

Internal $\mathrm{CO}_{2}$ partial pressures $\left(\mathrm{C}_{\mathrm{i}}\right)$ were estimated after von Caemmerer and Farquhar (1981). Net $\mathrm{CO}_{2}$ assimilation $\left(A_{n e t}\right)$ values were measured at the following values of $C_{a}: 400,300,200,100,50$, $25,0,600$, and $800 \mu \mathrm{mol} \mathrm{mol}^{-1}$. $\mathrm{A}_{\text {net }}$ was then plotted against the estimated $\mathrm{CO}_{2}$ concentrations at the sites of carboxylation in the mesophyll $\left(\mathrm{C}_{\mathrm{m}}\right)$ (i.e., by phosphoenolpyruvate carboxylase; PEPc). The maximal carboxylation capacity of PEPc $\left(V_{\text {pmax }}\right)$ was calculated from the initial slope of the $A \sim C_{m}$ curve (where $\mathrm{C}_{\mathrm{m}}<70 \mu \mathrm{mol} \mathrm{mol}^{-1}$ ) (von Caemmerer, 2000). Irradiance differed among individual plants because maximal $\mathrm{A}_{\text {net }}$ could not be achieved for drought-stressed plants at high irradiance. However, we note that $\mathrm{V}_{\mathrm{pmax}}$ is independent of the differences in irradiance used $\left(500-1800 \mu \mathrm{mol} \mathrm{m}^{-2} \mathrm{~s}^{-1}\right)$ (Leegood and von Caemmerer, 1989; Pfeffer and Peisker, 1998). Maximal, $\mathrm{CO}_{2}$-saturated rates of carbon assimilation are represented by the horizontal asymptote of the $\mathrm{A} \sim \mathrm{C}_{\mathrm{m}}$ curve and were fit with an exponential decay function, which provided a higher $R^{2}$ in this region of the curve than the more traditional non-rectangular hyperbola. All curve fitting was done using the "nls" function in R (R Core Team, 2015).

Chlorophyll fluorescence was measured prior to starting each A Ci curve. Quantum yield ( $\left.\Phi_{\mathrm{PSII}}\right)$ and the electron transport rate through photosystem II (ETR) were measured using the pulse-amplitude- 
modulation method (Schreiber et al., 1986). The fraction of absorbed quanta used by photosystem II was assumed to be 0.4 for all measurements, e.g., $\mathrm{C}_{4}$ plants in Earl and Tollenaar (1998). Temperature and VPD were kept at $23.7-29.0{ }^{\circ} \mathrm{C}$ and $1.42-1.98 \mathrm{kPa}$ for all measurements, respectively.

\subsection{Canopy temperature}

Canopy temperature and stomatal conductance were measured on 12 plants in the greenhouse (6 fullywatered and 6 water-stressed) during dry-down between March 4 and March 13, 2015 using a thermal camera (model A655sc, FLIR Systems Inc., Wilsonville, OR, USA). This was done to evaluate changes in leaf temperature as stomatal conductance (and evaporative cooling) declined during drought stress, and to ensure that changes in physiological functioning did not result directly from heat stress. In all instances, mean canopy temperature never exceeded $29^{\circ} \mathrm{C}$, which is far below the threshold where protein denaturation or photosynthetic down-regulation would be expected (Cunningham and Read, 2002; Salvucci et al., 2001).

Each day, between $1000 \mathrm{~h}$ and $1400 \mathrm{~h}$, plants at various values of $\Psi_{\text {leaf }}$ were removed from the greenhouse bench and placed on a cold background (frozen gel sheet) to provide thermal contrast between plant tissue and the ground. The thermal camera was mounted on a ceiling beam ca $2.5 \mathrm{~m}$ above the greenhouse floor and the plant was photographed under full greenhouse irradiance. Each image (Fig. S3) was processed by producing a frequency distribution of pixel temperatures, removing the cold background pixels, and extracting the mean from the resulting plant temperature pixels.

\subsection{Statistical analyses}

Bivariate relationships (e.g., $\mathrm{V}_{\text {pmax }} \sim \Psi_{\text {leaf }}$ ) were fit with linear ordinary least-squares models to assess the covariation between stress and plant response variables. Differences between treatments (fully-watered and drought-stress) may manifest as disparate slope or elevation coefficients, as well as shifts along a common fitted axis (Warton et al., 2006). The "smatr" package in R was used to test for treatment differences in slope, elevation (when slope differences were non-significant), as well as shifts along a 
common trendline when regression coefficients did not differ between treatments (R Core Team, 2015; Warton et al., 2006). The multivariate covariation among all photosynthesis and hydraulic traits was assessed using the "prcomp" function (principal components analysis) in R, after scaling all traits to unit variance (R Core Team, 2015). Traits values were transformed as necessary to meet the assumptions of the analyses.

\section{Results}

\subsection{How well is hydraulic functioning aligned with increasing leaf drought stress?}

Drought-stress treatments in the greenhouse resulted in marked reduction in whole plant transpiration seven days into the dry-down period (Fig. 1). Visual effects of drought stress included loss of turgor in leaves and stems (i.e., "flagging”), as well as pale leaf appearance when $\Psi_{\text {leaf }}$ fell below ca -2.5 MPa. Whole plant conductance decreased nonlinearly with decreasing leaf water potential (Fig. 2a). Losses of $50 \%$ and $80 \%$ of maximal conductance were associated with $\Psi_{\text {leaf }}$ values of -1.29 and $-1.82 \mathrm{MPa}$, respectively (Fig. 2a). $\Psi_{\text {leaf }}$ values lower than -2.5 MPa were associated near-negligible levels of whole plant conductance $\left(<5 \%\right.$ of maximal $\mathrm{K}_{\text {plant }}$ (Fig. 2a). Specific conductivity of stems (field plants) decreased similarly to whole plant conductance measured in the greenhouse. Losses of $50 \%$ and $80 \%$ of maximal conductance in stems were associated with $\Psi_{\text {leaf }}$ values of -1.15 and $-2.27 \mathrm{MPa}$ (Fig. 2b). We note that these values bracket the range commonly experienced by field-grown maize, which function at $\Psi_{\text {leaf }}$ values between -1.2 and -2.2 MPa during midday hours (DeJonge et al., 2015).

\footnotetext{
>> insert Fig. 1 here >> insert Fig. 2 here
}

\subsection{How well is photosynthetic functioning aligned with increasing leaf drought stress?}

Maximal activity of PEPc $\left(\mathrm{V}_{\mathrm{pmax}}\right)$ decreased linearly with decreasing $\Psi_{\text {leaf }}$ among greenhouse plants, exhibiting a $70 \%$ reduction at $\Psi_{\text {leaf }}$ of $-3.0 \mathrm{MPa}$ (Fig. 3). This is in contrast with modelled PEPc activity 
(Tuzet and Leuning, 2003) and observed electron transport (Zhou et al., 2013), which both declined nonlinearly in response to declining water potential, although Zhou et al. (2013) do report near-linear responses for some dicotyledon species. These reductions in $\mathrm{V}_{\text {pmax }}$ were also aligned with similar losses of $\mathrm{K}_{\text {plant }}\left(R^{2}=0.53 ; p=0.001\right)$, ETR $\left(R^{2}=0.53, p=0.002\right)$, as well as maximum net $\mathrm{CO}_{2}$ assimilation and stomatal conductance $\mathrm{g}_{s_{-} \max }$ (Tables $1 \& 2, \mathrm{~S} 4$ ). Quantum efficiency of net $\mathrm{CO}_{2}$ assimilation (i.e., mol $\mathrm{CO}_{2}$ fixed $\mathrm{mol}^{-1}$ electron transported through PSII) did not differ between treatments as estimated from the $\mathrm{A}_{\text {net }} \sim$ ETR slope coefficient for greenhouse or field plants $(p>0.05)$. This indicates that electron sinks (e.g., $\mathrm{CO}_{2}$ fixation, photorespiration) did not differ in proportion between stressed and well-watered plants. Rather, drought-stressed plants exhibited significant, but aligned, reductions in light reactions and Benson-Calvin cycle reactions. This is consistent with a previous report suggesting that the functioning of photosystem II and the Benson-Calvin cycle remain closely coordinated in maize across a wide range of environmental conditions (Edwards and Baker, 1993).

\author{
>> insert Fig. 3 here \\ >> insert Table 1 here \\ >> insert Table 2 here
}

Leaf temperature of greenhouse plants increased with decreasing stomatal conductance as plants dried-down, with temperatures ranging between ca 20 and $29^{\circ} \mathrm{C}$ (Fig. S5). This suggests that leaf temperatures did not approach levels representative of heat stress in angiosperms (Cunningham and Read, 2006; Salvucci et al., 2001) and that most of the variation in conductance and photochemistry reported here represent a drought-stress response.

\title{
3.3 Are reductions in whole plant conductance aligned with photosynthetic and stomatal functioning?
}

Whole plant conductance of greenhouse maize was positively correlated with stomatal conductance $\left(R^{2}=\right.$ $0.52 ; p=0.002)$, net $\mathrm{CO}_{2}$ assimilation $\left(R^{2}=0.63 ; p<0.001\right)$, electron transport rate $\left(R^{2}=0.53 ; p=\right.$ 0.002), and phosphoenolpyruvate carboxylase activity $\left(R^{2}=0.53 ; p=0.001\right)$ (Fig. 4). Furthermore, $83 \%$ 
of the combined variation in photosynthetic and hydraulic traits ( $\Psi_{\text {leaf }}, K_{\text {plant }}, g_{s_{-} \max }$, ETR, $\left.V_{\text {pmax }}, A_{\max }\right)$ was explained by a single principal component.

>> insert Fig. 4 here

\subsection{How quickly does maize recover from severe drought stress?}

Greenhouse-grown maize recovered quickly from significant loss of whole plant transpiration (Fig. 5). Four days after bringing the soil back up to $100 \%$ of field capacity, plants subjected to severe drought stress ( $\Psi_{\text {leaf }}$ values between -3.4 and $\left.-4.0 \mathrm{MPa}\right)$ were functioning at ca $90 \%$ of maximal whole plant transpiration (Fig. 5). Although xylem conductance and biochemical function were not measured in these "recovery" plants, these same levels of drought stress were associated with ca $90-95 \%$ reduction in whole plant conductance and a similar decline in biochemical functioning (Figs. 2a, 3). It is not known whether the prolonged dysfunction (after four days) is due to water transport, biochemistry, or other stress response.

>> insert Fig. 5 here

\section{Discussion}

\subsection{What traits are associated with meaningful reductions in $\mathrm{CO}_{2}$ assimilation during drought stress?}

There are at least three important considerations when answering this question: 1) processes that conserve water, 2) the efficiency with which water is used to produce photosynthate (Passioura and Angus, 2010), and 3) whether plants need to operate continuously under drought stress or just survive through brief periods of stress (Gleason et al., 2014; Xu et al., 2010). In addition, the question itself may be misleading if whole plant physiology is integrated in a way that results in multiple failures across more than one physiological process (e.g., biochemical, hydraulic). For example, much research has been focused in 
improving photochemical functioning during drought stress (Ashraf, 2010), but are these improvements in biochemical functioning likely to confer meaningful advances in biomass production if associations exist with other physiological traits that remain unimproved? Our results suggest close coordination between photochemistry (PEPc activity, ETR), stomatal conductance, and hydraulic conductance during drought stress, in both greenhouse and field populations. Intuitively, this should make sense, as all three physiological systems must function together to insure an adequate supply of $\mathrm{CO}_{2}$ and water. It is certainly a strong possibility that improvements to one trait will result in the failure of some other "linked" system component, rather than leading to improved growth.

\subsection{Conserving water}

It is clear that the water use efficiency of maize declines substantially as $\mathrm{CO}_{2}$ assimilation increases (Bunce, 2010), i.e., the top of the curve in Fig. S6. Reducing water use by half (i.e., reducing stomatal conductance by $\approx 50 \%$ at a given evaporative demand) would result in only a $20-30 \%$ reduction in net $\mathrm{CO}_{2}$ assimilation as a consequence. Clearly, this would be a good strategy, particularly in habitats (i.e., farms) where the linear cost associated with additional water input exceeds the diminishing benefit derived from operating in the flatter portion of the production function (i.e. Fig. S6). For example, limited irrigation management could be used to maintain stomatal conductance in the near-linear phase of the $\mathrm{A}_{\text {net }} \sim \mathrm{gs}$ response curve (ca gs $<0.17 \mathrm{~mol} \mathrm{~m}^{-2} \mathrm{~s}^{-1}$ ). We suggest that reduced stomatal conductance would also benefit dry-land farmers who anticipate long periods of moderately stressed crops, as others have suggested (Bunce, 2010), particularly if photosynthetic capacity and water use efficiency can also be improved (Gilbert et al., 2011a; Gilbert et al., 2011b).

\subsection{Using water during stress - links among $\mathrm{CO}_{2}$ assimilation, whole plant conductance, and xylem functioning}

Stomatal conductance cannot continue without a supply of water through the xylem. Much research is focused on the importance of xylem functioning to supply this water, as well as the consequences of its 
failure (Blackman et al., 2009; Brodribb et al., 2010; Choat, 2013; Gleason et al., 2012; Lens et al., 2013). These studies, as well as the results reported here, emphasize the importance of xylem conductance in contrast with other plant traits that can be regulated or repaired after extreme drought stress. Xylem vessels are comprised of dead cells. In monocotyledons like maize, xylem cannot be augmented via secondary growth. The xylem a maize plant produces must be functional throughout its life, i.e., embolism must be avoided or repaired. As such, we might expect close regulation of water loss (i.e., stomatal regulation) to prevent irreversible damage to the water transport pathway (Lens et al., 2013). It is possible that maize is too conservative with its water during moderate levels of stress (i.e., $\Psi_{\text {leaf }}$ values between -0.5 and -1.0 MPa). However, even at $\Psi_{\text {leaf }}$ values of -2.0 MPa, maize has already lost more than $80 \%$ of its stem and whole plant conductance. It is unlikely that the maintenance of stomatal conductance at leaf water potentials lower than -2.0 MPa would lead to higher rates of photosynthesis, but would rather lead to further decline in water transport, and perhaps to a cascade of other physiological failures (e.g., PEPc functioning, light harvesting, electron transport, membrane integrity, etc).

\subsection{Surviving through brief periods of severe stress}

Biochemical functioning and stomatal conductance both rebound quickly in maize when moderate stress $\left(\Psi_{\text {leaf }} \approx-1.6 \mathrm{MPa}\right)$ is lifted (Lal and Edwards, 1996), as has also been found in other monocotyledon species (Stiller et al., 2003; Xu et al., 2009a, b). Our study adds to these previous efforts by demonstrating that leaf conductance may recover quickly from severe stress $\left(\Psi_{\text {leaf }} \approx-3.5 \mathrm{MPa}\right)$, being only moderately reduced (ca. $90 \%$ of maximal) 4 days after re-watering. It is known that dicotyledon and monocotyledon leaf and stem conductance may recover speedily (i.e., from 1 hour to 3 days) from moderate stress after re-watering (Blackman et al., 2009; Knipfer et al., 2016; Stiller et al., 2003). Although little is known about the recovery of monocotyledon xylem under severe stress, xylem of woody dicotyledons and gymnosperms may become permanently damaged and unserviceable for water transport (Blackman et al., 2009; Brodribb et al., 2010; Brodribb and Cochard, 2009; Ogasa et al., 2013). 
Apart from the apparent role of xylem refilling/recovery following drought stress, it is likely that a large portion of whole plant resistance that builds during drought stress arises from tissues outside the xylem. Extraxylary resistance in leaves may manifest via aquaporin down-regulation across lipid membranes (Kim and Steudle, 2009) or the physical shrinkage of mesophyll and extraxylary spaces during desiccation (Bouche et al., 2016; Scoffoni et al., 2014), possibly associated with the elasticity of mesophyll cell walls (Trifiló et al., 2016). As such, high resistance in extraxylary tissues during midday hours could result in xylem water potentials of stems that are significantly higher than that measured in leaves. However, we note that losses of conductance in whole maize plants and stems (xylem conductance), and confirmed via $\mu$-CT imaging, all support the conclusion that xylem conductance loss is likely significant at water potentials $<-1.0 \mathrm{MPa}$, but is also recoverable. Although most evidence for the loss and recovery of plant conductance comes from dicotyledon species, it is likely that the mechanisms leading to irreversible and reversible losses of conductance are similar between these two angiosperm clades. Thus, we suggest that although xylem and photochemical functioning are likely to survive easily through brief periods of moderate stress, prolonged periods of extreme stress ( $\Psi_{\text {leaf }}<-2.5 \mathrm{MPa}$ ) will likely result in damage to the hydraulic network, i.e., xylem.

\subsection{The way forward}

Maize functioning under continuous drought stress in rain-fed or deficit irrigated cropping systems would likely benefit from reduced stomatal conductance and selection for increased photosynthetic capacity, similar as that recently suggested for soybean (Gilbert et al., 2011b). Breeding/transgenic strategies targeting rain-fed climates, where short severe stress may develop and then lessen, may benefit from genotypes exhibiting robust xylem, capable of surviving low water potentials $(<-4.0 \mathrm{MPa})$ without permanent damage. This level of drought resistance is not at all uncommon among other monocotyledon species, i.e., the genes coding for this level of resistance exist. Future efforts to improve the performance of maize in drought-prone environments would benefit from a whole plant perspective that incorporates biochemical functioning, as well as the transport of water to maintain this functioning. 


\section{Acknowledgements}

We would like to warmly thank Jon Altenhofen from the Northern Colorado Water Conservancy District for providing constructive feedback on the results of this study and for giving us the "farmer's perspective" of maize production. We also extend thanks to Matt Abbitt, Cory Arnold, Tammy Brenner, Liam Cummins, Elliot Demos, Bailey Kraich, John Lambert, Kayla Moden, and April Shelhon from the USDA-ARS research laboratory for their kind assistance with our greenhouse experiment. This research was funded by the USDA-ARS.

\section{References}

Ainsworth, E.A., Rogers, A., 2007. The response of photosynthesis and stomatal conductance to rising $\left[\mathrm{CO}_{2}\right]$ : mechanisms and environmental interactions. Plant Cell Environ. 30, 258-270.

Almeida, G. et al. (10 authors), 2014. Molecular mapping across three populations reveals a QTL hotspot region on chromosome 3 for secondary traits associated with drought tolerance in tropical maize. Mol. Breed. 34, 701-715.

Aphalo, P.J., Jarvis, P.G., 1991. Do stomata respond to relative humidity? Plant Cell Environ. 14, 127132.

Ashraf, M., 2010. Inducing drought tolerance in plants: recent advances. Biotechnol. Adv. 28, 169-183.

Ball, J.T., Woodrow, I.E., Berry, J.A., 1987. A model predicting stomatal conductance and its contribution to the control of photosynthesis under different environmental conditions. In: 
Biggens, I. (Ed.), Progress in Photosynthesis Research. Martinus-Nijhoff Publishers, Dordrecht, The Netherlands, pp. 221-224.

Blackman, C.J., Brodribb, T.J., Jordan, G.J., 2009. Leaf hydraulics and drought stress: response, recovery and survivorship in four woody temperate plant species. Plant Cell Environ. 32, 1584-1595.

Bond, B.J., Kavanagh, K.L., 1999. Stomatal behavior of four woody species in relation to leaf-specific hydraulic conductance and threshold water potential. Tree Physiol. 19, 503-510.

Bouche, P.S. et al. (13 authors), 2016. Are needles of Pinus pinaster more vulnerable to xylem embolism than branches? New insights from X-ray computed tomography. Plant Cell Environ. 39, 860-870.

Brodribb, T.J., Cochard, H., 2009. Hydraulic failure defines the recovery and point of death in waterstressed conifers. Plant Physiol. 149, 575-584.

Brodribb, T.J., McAdam, S.A.M., 2011. Passive origins of stomatal control in vascular plants. Science $331,582-585$.

Brodribb, T.J., Bowman, D.M.J.S., Nichols, S., Delzon, S., Burlett, R., 2010. Xylem function and growth rate interact to determine recovery rates after exposure to extreme water deficit. New Phytol. 188, 533-542.

Bunce, J.A., 2010. Leaf transpiration efficiency of some drought-resistant maize lines. Crop Sci. 50, 1409-1413.

Castiglioni, P. et al. (17 authors), 2008. Bacterial RNA chaperones confer abiotic stress tolerance in plants and improved grain yield in maize under water-limited conditions. Plant Physiol. 147, 446-455.

Charra-Vaskou, K., Badel, E., Burlett, R., Cochard, H., Delzon, S., Mayr, S., 2012. Hydraulic efficiency and safety of vascular and non-vascular components in Pinus pinaster leaves. Tree Physiol. 32, 1161-1170. 
Choat, B., 2013. Predicting thresholds of drought-induced mortality in woody plant species. Tree Physiol. $33,669-671$.

Choat, B. et al. (23 authors), 2012. Global convergence in the vulnerability of forests to drought. Nature 491, 752-755.

Choat, B., Lahr, E.C., Melcher, P.J., Zwieniecki, M.A., Holbrook, N.M., 2005. The spatial pattern of air seeding thresholds in mature sugar maple trees. Plant Cell Environ. 28, 1082-1089.

Cochard, H., 2002. Xylem embolism and drought-induced stomatal closure in maize. Planta 215, 466471.

Cunningham, S.C., Read, J., 2002. Comparison of temperate and tropical rainforest tree species: photosynthetic responses to growth temperature. Oecologia 133, 112-119.

Cunningham, S.C., Read, J., 2006. Foliar temperature tolerance of temperate and tropical evergreen rain forest trees of Australia. Tree Physiol. 26, 1435-1443.

Damour, G., Simonneau, T., Cochard, H., Urban, L., 2010. An overview of models of stomatal conductance at the leaf level. Plant Cell Environ. 33, 1419-1438.

DeJonge, K.C., Taghvaeian, S., Trout, T.J., Comas, L.H., 2015. Comparison of canopy temperature-based water stress indices for maize. Agric. Water Manag. 156, 51-62.

Earl, H.J., Tollenaar, M., 1998. Relationship between thylakoid electron transport and photosynthetic $\mathrm{CO}_{2}$ uptake in leaves of three maize (Zea mays L.) hybrids. Photosynth. Res. 58, 245-257.

Edwards, G.E., Baker, N.R., 1993. Can $\mathrm{CO}_{2}$ assimilation in maize leaves be predicted accurately from chlorophyll fluorescence analysis? Photosynth. Res. 37, 89-102.

Flexas, J., Medrano, H., 2002. Drought-inhibition of photosynthesis in C3 plants: stomatal and nonstomatal limitations revisited. Ann. Bot. 89, 183-189. 
Ghannoum, O., 2009. C 4 photosynthesis and drought stress. Ann. Bot. 103, 635-644.

Gilbert, M.E., Holbrook, N.M., Zwieniecki, M.A., Sadok, W., Sinclair, T.R., 2011a. Field confirmation of genetic variation in soybean transpiration response to vapor pressure deficit and photosynthetic compensation. Field Crops Res. 124, 85-92.

Gilbert, M.E., Zwieniecki, M.A., Holbrook, N.M., 2011b. Independent variation in photosynthetic capacity and stomatal conductance leads to differences in intrinsic water use efficiency in 11 soybean genotypes before and during mild drought. J. Exp. Bot. 62, 2875-2887.

Gleason, S., Butler, D.W., Ziemińska, K., Waryszak, P., Westoby, M., 2012. Stem xylem conductivity is key to plant water balance across Australian angiosperm species. Funct. Ecol. 26, 343-352.

Gleason, S.M., 2015. Evolutionary outcomes should inform strategies to increase drought tolerance. Nature Plants 1, 15114.

Gleason, S.M., Blackman, C.J., Cook, A.M., Laws, C.A., Westoby, M., 2014. Whole-plant capacitance, embolism resistance and slow transpiration rates all contribute to longer desiccation times in woody angiosperms from arid and wet habitats. Tree Physiol. 34, 275-285.

Gleason, S.M., Butler, D.W., Waryszak, P., 2013. Shifts in leaf and stem hydraulic traits across aridity gradients in eastern Australia. Int. J. Plant Sci. 174, 1292-1301.

Grassi, G., Magnani, F., 2005. Stomatal, mesophyll conductance and biochemical limitations to photosynthesis as affected by drought and leaf ontogeny in ash and oak trees. Plant Cell Environ. $28,834-849$.

Hanson, A.D., Hitz, W.D., 1982. Metabolic responses of mesophytes to plant water deficits. Annu. Rev. Plant Physiol. 33, 163-203. 
Jupa, R., Baláž, M., Svoboda, P., Gloser, V., 2013. Inherent variability in structural and functional traits of xylem among three hop varieties. Plant Soil Environ. 59, 273-279.

Kim, Y.X., Steudle, E., 2009. Gating of aqùaporins by light and reactive oxygen species in leaf parenchyma cells of the midrib of Zea mays. J. Exp. Bot. 60, 547-556.

Knipfer, T., Cuneo, I.F., Brodersen, C.R., McElrone, A.J., 2016. In situ visualization of the dynamics in xylem embolism formation and removal in the absence of root pressure: a study on excised grapevine stems. Plant Physiol. 171, 1024-1036.

Kotakis, C., Theodoropoulou, E., Tassis, K., Oustamanolakis, C., Ioannidis, N., Kotzabasis, K., 2014. Putrescine, a fast-acting switch for tolerance against osmotic stress. J. Plant Physiol. 171, 48-51.

Lal, A., Edwards, G.E., 1996. Analysis of inhibition of photosynthesis under drought stress in the $\mathrm{C}_{4}$ species Amaranthus cruentus and Zea mays: electron transport, $\mathrm{CO}_{2}$ fixation and carboxylation capacity. Aust. J. Plant Physiol. 23, 403-412.

Lamy, J.-B., Bouffier, L., Burlett, R., Plomion, C., Cochard, H., 2011. Uniform selection as a primary force reducing population genetic differentiation of cavitation resistance across a species range. PLoS ONE 6, e23476.

Lamy, J.-B., Delzon, S., Bouche, P.S., Alia, R., Vendramin, G.G., Cochard, H., Plomion, C., 2014. Limited genetic variability and phenotypic plasticity detected for cavitation resistance in a Mediterranean pine. New Phytol. 201, 874-886.

Leakey, A.D.B., Uribelarrea, M., Ainsworth, E.A., Naidu, S.L., Rogers, A., Ort, D.R., Long, S.P., 2006. Photosynthesis, productivity, and yield of maize are not affected by open-air elevation of $\mathrm{CO}_{2}$ concentration in the absence of drought. Plant Physiol. 140, 779-790. 
Lee, S.-H. et al. (7 authors), 2015. Identification and functional characterization of Siberian wild rye (Elymus sibiricus L.) small heat shock protein 16.9 gene (EsHsp16.9) conferring diverse stress tolerance in prokaryotic cells. Biotechnol. Lett. 37, 881-890.

Leegood, R.C., von Caemmerer, S., 1989. Some relationships between contents of photosynthetic intermediates and the rate of photosynthetic carbon assimilation in leaves of Zea mays L. Planta $178,258-266$.

Lens, F., Tixier, A., Cochard, H., Sperry, J.S., Jansen, S., Herbette, S., 2013. Embolism resistance as a key mechanism to understand adaptive plant strategies. Curr. Opin. Plant Biol. 16, 287-292.

Markelz, R.J.C., Strellner, R.S., Leakey, A.D.B., 2011. Impairment of $\mathrm{C}_{4}$ photosynthesis by drought is exacerbated by limiting nitrogen and ameliorated by elevated $\left[\mathrm{CO}_{2}\right]$ in maize. J. Exp. Bot. 62, $3235-3246$.

McCormick, A.J., Cramer, M.D., Watt, D.A., 2008. Changes in photosynthetic rates and gene expression of leaves during a source-sink perturbation in sugarcane. Ann. Bot. 101, 89-102.

McMullen, M.D. et al. (30 authors), 2009. Genetic properties of the maize nested association mapping population. Science $325,737-740$.

Medlyn, B.E. et al. (9 authors), 2011. Reconciling the optimal and empirical approaches to modelling stomatal conductance. Glob. Change Biol. 17, 2134-2144.

Mencuccini, M., Minunno, F., Salmon, Y., Martínez-Vilalta, J., Hölttä, T., 2015. Coordination of physiological traits involved in drought-induced mortality of woody plants. New Phytol. DOI: 10.1111/nph.13461.

Nardini, A., Salleo, S., 2000. Limitation of stomatal conductance by hydraulic traits: sensing or preventing xylem cavitation? Trees Struct. Funct. 15, 14-24. 
Ogasa, M., Miki, N.H., Murakami, Y., Yoshikawa, K., 2013. Recovery performance in xylem hydraulic conductivity is correlated with cavitation resistance for temperate deciduous tree species. Tree Physiol. 33, 335-344.

Pammenter, N.W., Vander Willigen, C., 1998. A mathematical and statistical analysis of the curves illustrating vulnerability of xylem to cavitation. Tree Physiol. 18, 589-593.

Passioura, J.B., Angus, J.F., 2010. Improving productivity of crops in water-limited environments. In: Sparks, D.L. (Ed.), Adv. Agron. Academic Press, Waltham, USA, pp. 37-75.

Peiffer, J.A. et al. (10 authors), 2014. The genetic architecture of maize height. Genetics 196, 1337-1356.

Pfeffer, M., Peisker, M., 1998. $\mathrm{CO}_{2}$ gas exchange and phosphoenolpyruvate carboxylase activity in leaves of Zea mays L. Photosynth. Res. 58, 281-291.

Pinheiro, C., Chaves, M.M., 2011. Photosynthesis and drought: can we make metabolic connections from available data? J. Exp. Bot. 62, 869-882.

R Core Team, 2015. R: a Language and Environment for Statistical Computing. R Foundation for Statistical Computing, Vienna, Austria.

Robin, S. et al. (7 authors), 2003. Mapping osmotic adjustment in an advanced back-cross inbred population of rice. Theor. Appl. Genet. 107, 1288-1298.

Rosner, S., Klein, A., Müller, U., Karlsson, B., 2007. Hydraulic and mechanical properties of young Norway spruce clones related to growth and wood structure. Tree Physiol. 27, 1165-1178.

Rowland, L. et al. (8 authors), 2015. Death from drought in tropical forests is triggered by hydraulics not carbon starvation. Nature 528, 119-122.

Sack, L., Cowan, P.D., Jaikumar, N., Holbrook, N.M., 2003. The 'hydrology' of leaves: co-ordination of structure and function in temperate woody species. Plant Cell Environ. 26, 1343-1356. 
Salvucci, M.E., Osteryoung, K.W., Crafts-Brandner, S.J., Vierling, E., 2001. Exceptional sensitivity of rubisco activase to thermal denaturation in vitro and in vivo. Plant Physiol. 127, 1053-1064.

Schnable, P.S. et al. (156 authors), 2009. The B73 maize genome: complexity, diversity, and dynamics. Science 326, 1112-1115.

Schreiber, U., Schliwa, U., Bilger, W., 1986. Continuous recording of photochemical and nonphotochemical chlorophyll fluorescence quenching with a new type of modulation fluorometer. Photosynth. Res. 10, 51-62.

Scoffoni, C., Vuong, C., Diep, S., Cochard, H., Sack, L., 2014. Leaf shrinkage with dehydration: coordination with hydraulic vulnerability and drought tolerance. Plant Physiol. 164, 1772-1788.

Shane, M.W., McCully, M.E., Canny, M.J., 2000. The vascular system of maize stems revisited: implications for water transport and xylem safety. Ann. Bot. 86, 245-258.

Singh, M., Kumar, J., Singh, S., Singh, V.P., Prasad, S.M., 2015. Roles of osmoprotectants in improving salinity and drought tolerance in plants: a review. Reviews in Environmental Science and Bio/Technology 14, 407-426.

Song, Y., Chen, Q., Ci, D., Shao, X., Zhang, D., 2014. Effects of high temperature on photosynthesis and related gene expression in poplar. BMC Plant Biol. 14, 111.

Stiller, V., Lafitte, H.R., Sperry, J.S., 2003. Hydraulic properties of rice and the response of gas exchange to drought stress. Plant Physiol. 132, 1698-1706.

Trifiló, P., Raimondo, F., Savi, T., Lo Gullo, M.A., Nardini, A., 2016. The contribution of vascular and extra-vascular water pathways to drought-induced decline of leaf hydraulic conductance. J. Exp. Bot. 
Tuzet, A., Leuning, R., 2003. A coupled model of stomatal conductance, photosynthesis and transpiration. Plant Cell Environ. 26, 1097-1116.

Umezawa, T., Fujita, M., Fujita, Y., Yamaguchi-Shinozaki, K., Shinozaki, K., 2006. Engineering drought tolerance in plants: discovering and tailoring genes to unlock the future. Curr. Opin. Biotechnol. $17,113-122$.

Vico, G., Porporato, A., 2008. Modelling $\mathrm{C}_{3}$ and $\mathrm{C}_{4}$ photosynthesis under water-stressed conditions. Plant Soil 313, 187-203.

von Caemmerer, S., 2000. Biochemical Models of Leaf Photosynthesis. CSIRO Publishing, Collingwood, Australia.

von Caemmerer, S., Farquhar, G.D., 1981. Some relationships between the biochemistry of photosynthesis and the gas exchange of leaves. Planta 153, 376-387.

Warton, D.I., Wright, I.J., Falster, D.S., Westoby, M., 2006. Bivariate line-fitting methods for allometry. Biological Reviews 81, 259-291.

Wheeler, J.K., Huggett, B.A., Tofte, A.N., Rockwell, F.E., Holbrook, N.M., 2013. Cutting xylem under tension or supersaturated with gas can generate PLC and the appearance of rapid recovery from embolism. Plant Cell Environ. 36, 1938-1949.

Wortemann, R. et al. (8 authors), 2011. Genotypic variability and phenotypic plasticity of cavitation resistance in Fagus sylvatica L. across Europe. Tree Physiol. 31, 1175-1182.

Xu, Z., Zhou, G., Shimizu, H., 2010. Plant responses to drought and rewatering. Plant Signaling \& Behavior 5, 649-654.

Xu, Z.Z., Zhou, G.S., Shimizu, H., 2009a. Are plant growth and photosynthesis limited by pre-drought following rewatering in grass? J. Exp. Bot. 60, 3737-3749. 
Xu, Z.Z., Zhou, G.S., Shimizu, H., 2009b. Effects of soil drought with nocturnal warming on leaf stomatal traits and mesophyll cell ultrastructure of a perennial grass. Crop Sci. 49, 1843-1851.

Yan, J., He, C., Wang, J., Mao, Z., Holaday, S.A., Allen, R.D., Zhang, H., 2004. Overexpression of the arabidopsis 14-3-3 protein GF14 $\lambda$ in cotton leads to a "stay-green" phenotype and improves stress tolerance under moderate drought conditions. Plant Cell Physiol. 45, 1007-1014.

Yu, J., Holland, J.B., McMullen, M.D., Buckler, E.S., 2008. Genetic design and statistical power of nested association mapping in maize. Genetics 178, 539-551.

Zhang, Y.-J., Meinzer, F.C., Qi, J.-H., Goldstein, G., Cao, K.-F., 2013. Midday stomatal conductance is more related to stem rather than leaf water status in subtropical deciduous and evergreen broadleaf trees. Plant Cell Environ. 36, 149-158.

Zhou, S., Duursma, R.A., Medlyn, B.E., Kelly, J.W.G., Prentice, I.C., 2013. How should we model plant responses to drought? An analysis of stomatal and non-stomatal responses to drought stress. Agric. For. Meteorol. 182-183, 204-214. 


\section{Supporting information}

Additional Supporting Information may be found in the online version of this article:

Figure S1 Mass loss plots of plants in constant-climate chamber.

Figure S2 X-ray microtomography $(\mu-\mathrm{CT})$ images of stress and non-stressed stems.

Figure S3 Thermal images of maize canopies under greenhouse light during midday.

Figure S4 Decline in net $\mathrm{CO}_{2}$ assimilation and stomatal conductance with leaf water potential.

Figure S5 Relationship between stomatal conductance and mean canopy temperature.

Figure S6 Comparison of maximal net assimilation vs stomatal conductance curves. 


\section{Tables}

Table 1. Correlation matrix for all hydraulic and photosynthesis measurements taken on greenhouse plants. Pearson's $r$ statistic is given below diagonal and $p$ values are given above diagonal. $\Psi_{\text {leaf }}=$ leaf water potential immediately prior to measuring whole plant conductance (K $\left.\mathrm{K}_{\text {plant}}\right)$ and photosynthesis. $\mathrm{A}_{\max }=$ maximal rate of net $\mathrm{CO}_{2}$ assimilation. $\mathrm{gs} \max =$ maximal stomatal conductance. $\quad \mathrm{V}_{\mathrm{pmax}}=$ maximal activity of PEPc. $\mathrm{ETR}=$ maximal electron transport rate.

\begin{tabular}{lrrrrrr} 
& \multicolumn{1}{c}{$\Psi_{\text {leaf }}$} & \multicolumn{1}{c}{$A_{\max }$} & \multicolumn{1}{l}{$\mathrm{gs}_{\max }$} & \multicolumn{1}{l}{$\mathrm{V}_{\text {pmax }}$} & \multicolumn{1}{l}{ ETR } & \multicolumn{1}{c}{$K_{\text {plant }}$} \\
\hline$\Psi_{\text {leaf }}$ & 1 & 0.001 & 0.003 & $<0.001$ & 0.002 & 0.001 \\
$A_{\max }$ & 0.71 & 1 & $<0.001$ & $<0.001$ & $<0.001$ & $<0.001$ \\
gs $_{\max }$ & 0.65 & 0.87 & 1 & $<0.001$ & 0.001 & 0.002 \\
$\mathrm{~V}_{\text {pmax }}$ & 0.78 & 0.85 & 0.76 & 1 & 0.001 & 0.001 \\
ETR & 0.71 & 0.78 & 0.71 & 0.74 & 1 & 0.002 \\
$K_{\text {plant }}$ & 0.73 & 0.80 & 0.72 & 0.72 & 0.73 & 1 \\
\hline
\end{tabular}


Table 2. Correlation matrix for all photosynthesis measurements taken on field plants. Pearson's $r$ statistic is given below diagonal and $\mathrm{p}$ values are given above diagonal. $\mathrm{A}_{\max }=$ maximal rate of net $\mathrm{CO}_{2}$ assimilation. $\mathrm{gs}_{\max }=$ maximal stomatal conductance. $\mathrm{V}_{\mathrm{pmax}}=$ maximal activity of PEPc. ETR = maximal electron transport rate.

\begin{tabular}{lrrrr} 
& \multicolumn{1}{c}{$A_{\max }$} & \multicolumn{1}{c}{$\mathrm{gS}_{\max }$} & \multicolumn{1}{l}{$\mathrm{V}_{\text {pmax }}$} & \multicolumn{1}{l}{ ETR } \\
\hline$A_{\max }$ & 1 & $<0.001$ & 0.002 & $<0.001$ \\
$\mathrm{gS}_{\max }$ & 0.94 & 1 & $<0.001$ & $<0.001$ \\
$\mathrm{~V}_{\text {pmax }}$ & 0.58 & 0.78 & 1 & 0.036 \\
$\mathrm{ETR}$ & 0.94 & 0.86 & 0.51 & 1 \\
\hline
\end{tabular}




\section{Figure Legends}

Fig. 1 Diurnal responses of whole plant transpiration (expressed per unit leaf area) at 12 days into the greenhouse dry-down (January 17) and towards the end of dry-down (January 23). Grey symbols denote three drought-stressed plants. Black symbols denote three fully-watered plants. Small grey circles denote the vapor pressure deficit of the air. Each symbol represents a 15-min mean value for an individual plant.

Fig. 2 Losses of whole plant conductance of greenhouse plants (expressed per unit leaf area) (a) and specific-conductivity of stems (b) as a function of leaf water potential. Leaf water potentials at which $50 \%$ of conductance is lost are identified with broken lines. Grey symbols denote drought-stressed plants, whereas open symbols denote measurements on fully-watered plants.

Fig. 3 The maximal activity of PEPc $\left(\mathrm{V}_{\mathrm{pmax}}\right)$ under increasing drought stress (estimated by $\left.\Psi_{\text {leaf }}\right)$. White and grey circles denote individual plants in fully watered and drought-stressed treatments, respectively. Field values are shown with error bars $( \pm 1 \mathrm{SD})$ because paired $\Psi_{\text {leaf }}$ and $\mathrm{V}_{\text {pmax }}$ measurements were not available for individual plants. $\mathrm{V}_{\mathrm{pmax}}$ activity was modeled from $\mathrm{A} \sim \mathrm{C}_{\mathrm{m}}$ curves after von Caemmerer (2000).

Fig. 4 Bivariate relationships between whole plant conductance (greenhouse plants) and maximal stomatal conductance (a), maximal net $\mathrm{CO}_{2}$ assimilation (b), maximal electron transport rate (c), and maximal phosphoenolpyruvate carboxylase activity $\left(\mathrm{V}_{\mathrm{pmax}}\right)(\mathrm{d})$. White and grey circles denote individual plants in fully watered and drought-stressed treatments, respectively. $V_{\text {pmax }}$ modeled from $A \sim C_{m}$ curves after von Caemmerer (2000). Rates of electron transport (ETR) estimated from leaf chlorophyll fluorescence. 
Fig. 5 Recovery trajectory of whole plant transpiration (greenhouse) from extreme drought stress ( $\Psi_{\text {leaf }}$ values between -3.4 and -4.0 MPa). Broken line indicates when drought-stressed plants were watered back up to $100 \%$ of field capacity. Maximal transpiration was calculated each day from well-watered plants not subjected to stress. Each open circle represents the mean response of three drought-stressed plants. Error bars represent $\pm 1 \mathrm{SD}$. 


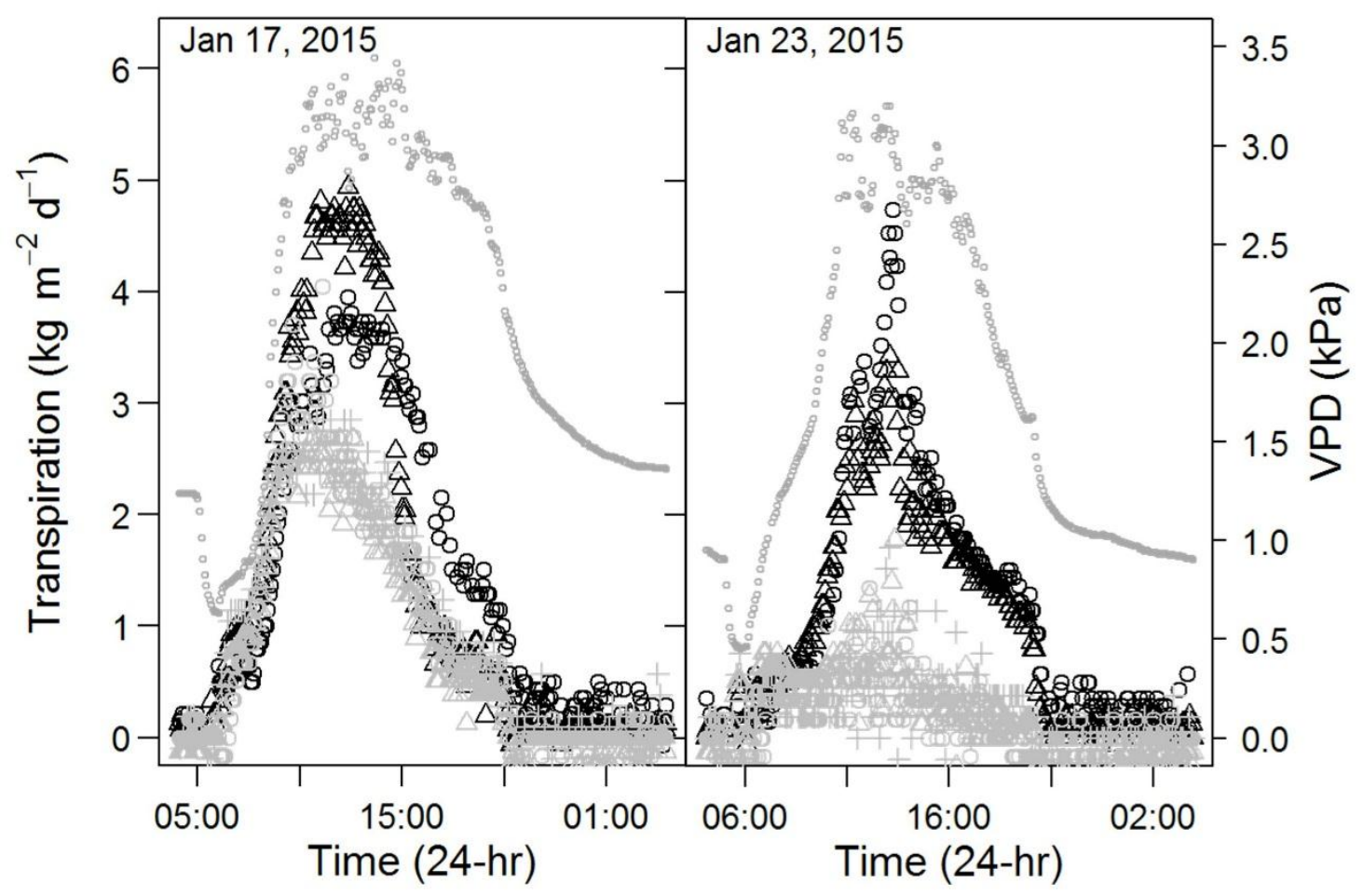



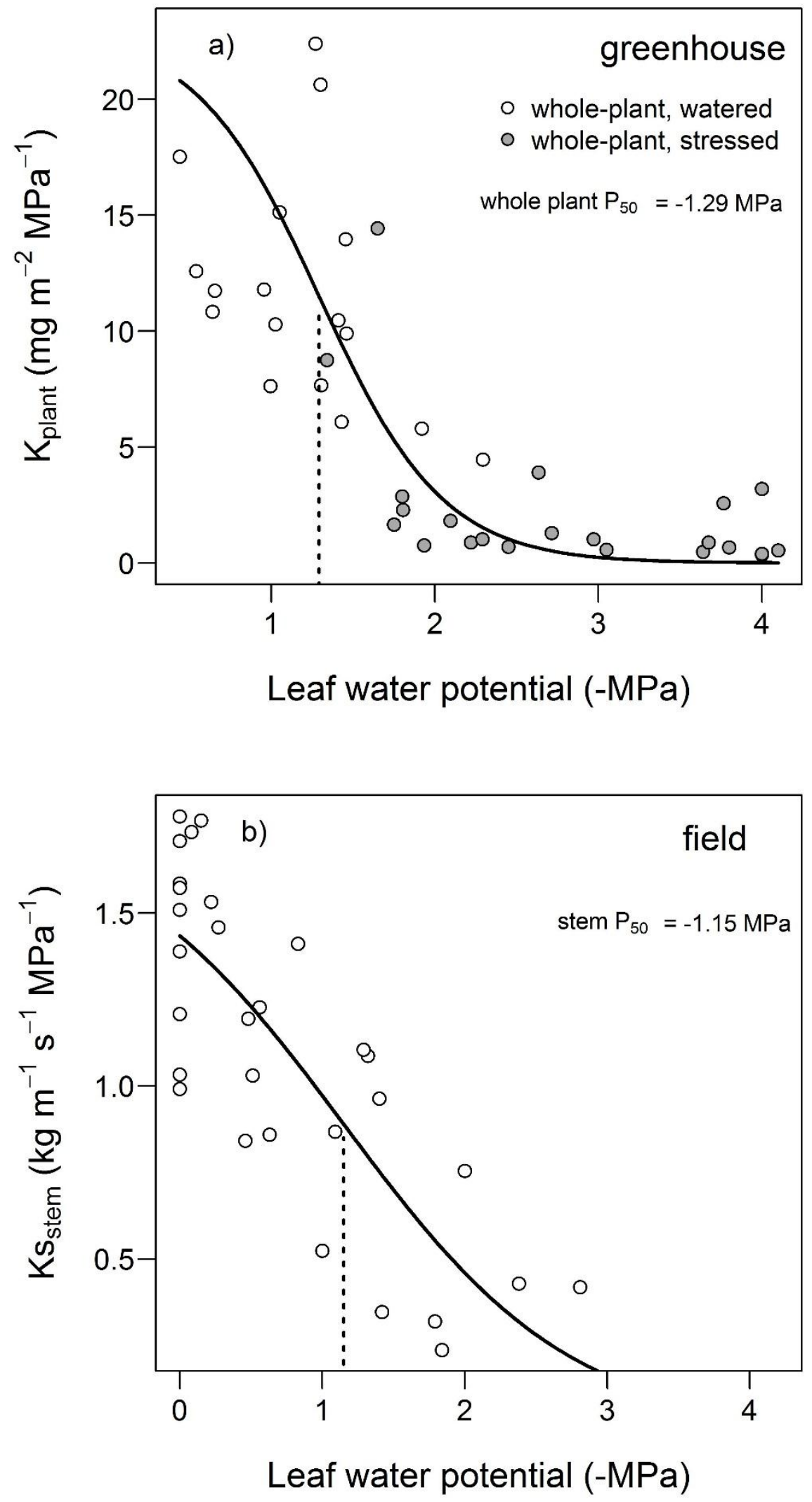


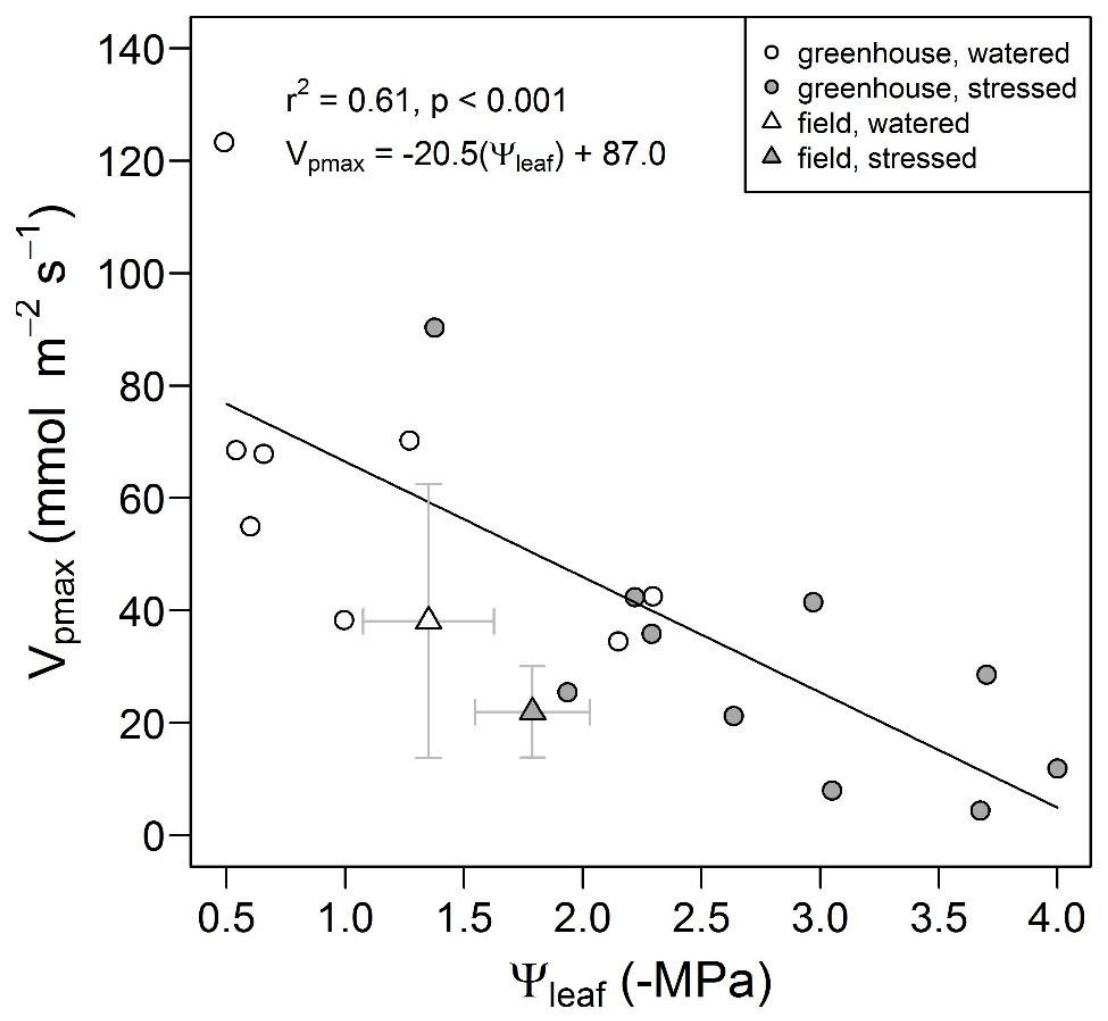



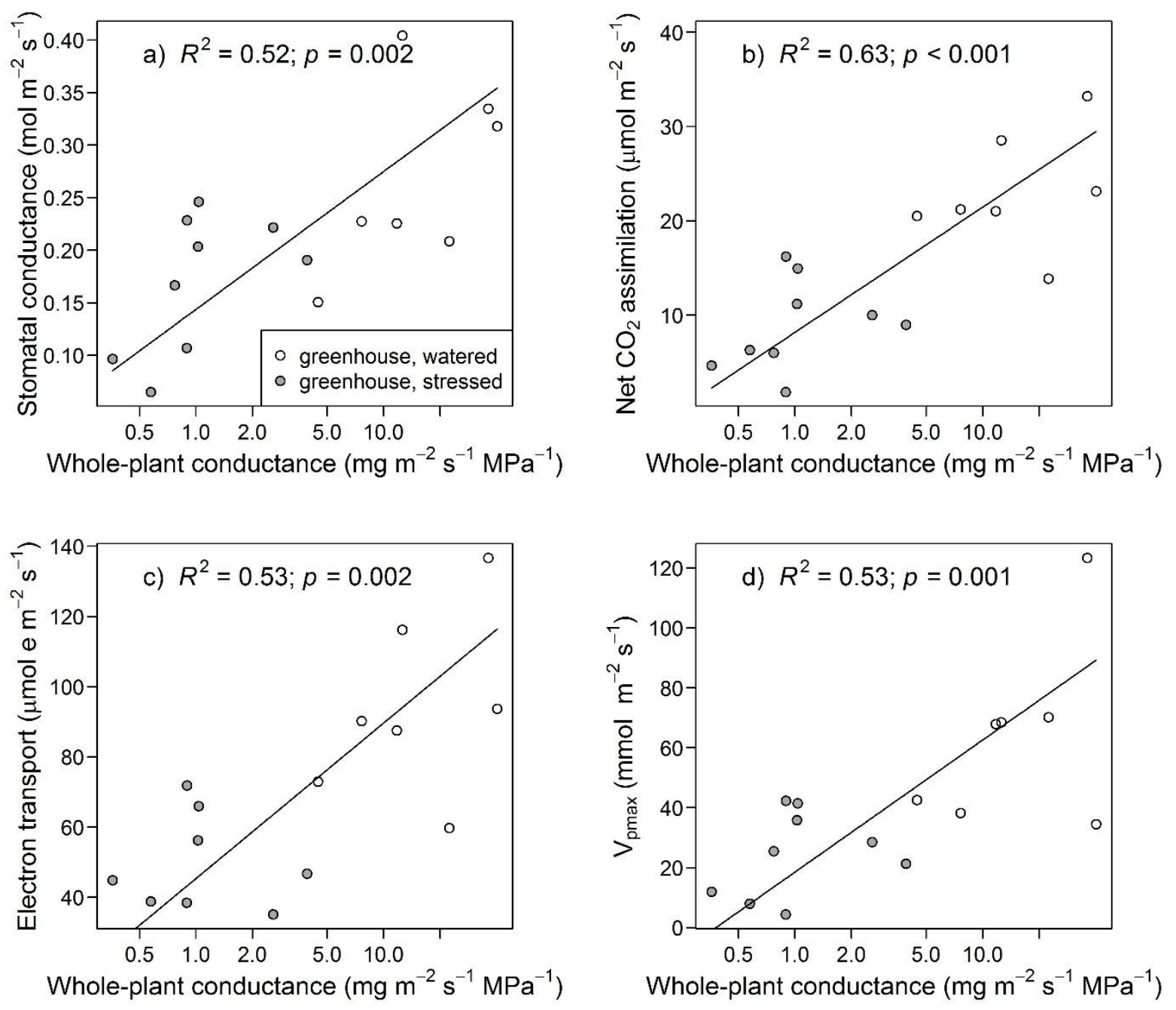


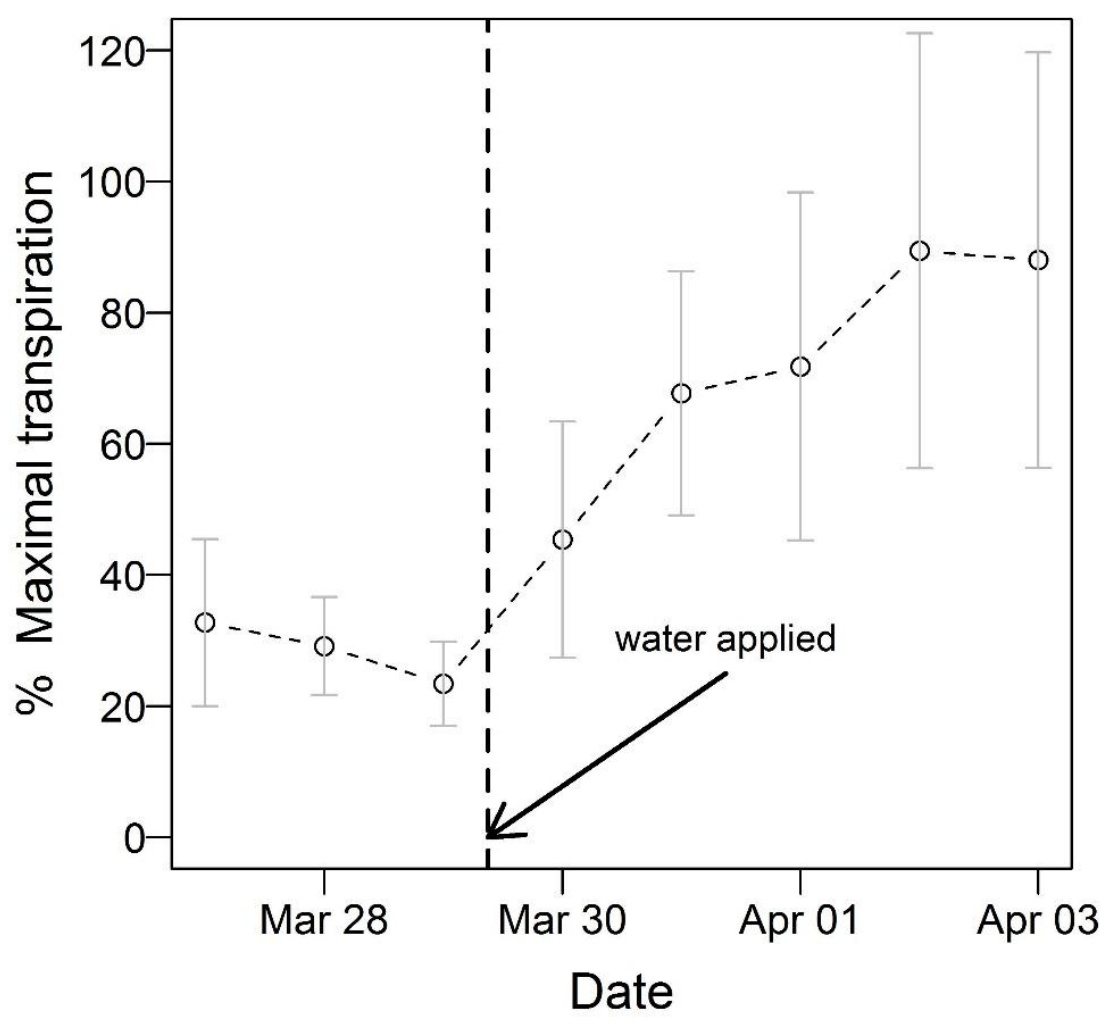

